\title{
Knockout of TRPV1 Exacerbates Ischemia-reperfusion-induced Renal Inflammation and Injury in Obese Mice
}

\author{
BEIHUA ZHONG ${ }^{1}$, SHUANGTAO MA ${ }^{1}$ and DONNA H. WANG ${ }^{1,2,3}$ \\ ${ }^{1}$ Division of Nanomedicine and Molecular Intervention, Department of Medicine, \\ Michigan State University, East Lansing, MI, U.S.A.; \\ ${ }^{2}$ Neuroscience Program, Michigan State University, East Lansing, MI, U.S.A.; \\ ${ }^{3}$ Cell \& Molecular Biology Program, Michigan State University, East Lansing, MI, U.S.A.
}

\begin{abstract}
Background/Aim: Transient receptor potential vanilloid type 1 (TRPVI) has anti-inflammatory properties. The present study aimed to investigate the role of TRPVI in renal inflammatory responses and tissue injury following renal ischemia-reperfusion $(I / R)$ in diet-induced obese mice. Materials and Methods: TRPV1 knockout and wild type mice were fed a normal or western diet (WD) for 23 weeks and were then subjected to renal I/R injury. Results: TRPVI knockout mice showed enhanced WD-induced renal macrophage infiltration and collagen deposition. Knocking out TRPVI exacerbated renal I/R-induced increase of malondialdehyde, interleukin-6, monocyte chemoattractant protein-1, and $N F-K B$ in obese mice. Similar results were observed in the expression of phosphorylated Smadl and Smad2/3. Blockade of calcitonin gene-related peptide (CGRP) receptors with CGRP8-37 worsened the I/R-induced renal inflammation and injury. Conclusion: Our data indicate that preserving TRPVI expression and function may prevent renal I/R injury in obesity likely through alleviating inflammatory responses.
\end{abstract}

Transient receptor potential vanilloid type 1 (TRPV1) is a nonselective calcium-permeable ion channel activated by hot temperature and capsaicin $(1,2)$. TRPV1 can also be activated by endogenous mediators that are related to inflammatory response and ischemia reperfusion (I/R)

This article is freely accessible online.

Correspondence to: Donna H. Wang, Division of Nanomedicine and Molecular Intervention, Department of Medicine, Michigan State University, 788 Service Rd., East Lansing, MI 48824, Michigan, U.S.A. Tel: +1 5174320797, Fax: +1 5174329250, e-mail: wangdo@msu.edu

Key Words: TRPV1, obesity, renal ischemia/reperfusion, calcitonin gene-related peptide, inflammation. protection $(2,3)$. Activation of TRPV1 induces release of neuropeptides, including calcitonin gene-related peptide (CGRP) and substance P (SP) (4). These neuropeptides have anti-inflammatory effects and may protect against I/R injury (5). CGRP-positive neurons are abundant in the kidney (6). TRPV1 deficiency results in aggravated inflammatory response and enhanced $\mathrm{I} / \mathrm{R}$ injury (7-9).

Western diet (WD, $42 \%$ calories from fat) intake increases morbidity of obesity, type 2 diabetes, and hypertension, all of which may contribute to end stage renal disease (10). Renal inflammation is the hallmark of most kidney diseases. WD is linked to activated nuclear factor kappa B (NF-kB) and increased tumor necrosis factor-alpha (TNF- $\alpha$ ) and interleukin-6 (IL-6) (11-13). Expression of phosphorylated Smad1 (p-Smad1) plays a role in the development of glomerulosclerosis and is related to the initiation and progression of diabetic nephropathy (14). Smad1 is highly expressed in diabetic nephropathy and advanced glycation end products induce the expression of Smad1 in glomeruli $(15$, 16). Phosphorylated $\operatorname{Smad} 2 / 3 \quad(\mathrm{p}-\mathrm{Smad} 2 / 3)$ is upregulated in obese rats (17). Smad3 is related to insulin resistance, and deficiency or inhibition of Smad3 protects against diet-induced obesity and insulin resistance (18).

Renal I/R injury is a main cause of acute renal failure with high mortality and morbidity (19). Renal I/R injury involves intrarenal leukocytic cell infiltration and increased proinflammatory cytokines, such as TNF- $\alpha$ and transforming growth factor- $\beta$ (TGF- $\beta$ ) (20). Diet-induced obesity exacerbates renal inflammation and $\mathrm{I} / \mathrm{R}$ injury (21). Acute renal ischemia increases the expression of Smad3, which is related to increased risk for chronic kidney disease (18). TRPV1-positive sensory nerves are impaired in obesity and diabetes. Obesity decreases the levels of sensory nervemediated vasodilatation $(22,23)$. We have shown that TRPV1 ablation aggravates renal inflammatory responses $(24,25)$. TRPV1 activation is related to protection against renal fibrosis via inhibition of the TGF- $\beta$-Smad $2 / 3$ signaling in deoxycorticosterone acetate (DOCA)-salt hypertension. 
Renal inflammation and fibrosis are hallmarks of renal injury and disease. Activation of the TGF- $\beta$-Smad 1 and/or smad2/3 signaling pathways as well as increased NF-kB p65 activity may play a key role in the pathogenesis of renal inflammation and fibrosis after renal injury.

We have reported that TRPV1 ameliorates renal I/R injury in obesity through increasing renal CGRP secretion and blood flow (10). However, the role of TRPV1 in inflammatory responses following renal ischemia-reperfusion injury in obese mice has not been reported. In the present study, we aimed to investigate the role of TRPV1 in I/Rinduced renal inflammatory responses and tissue injury in diet-induced obese mice.

\section{Materials and Methods}

Animals. All animal protocols were approved by the Institutional Animal Care and Use Committee of Michigan State University. Male TRPV1 gene knockout (TRPV $1^{-l-}$ ) mice and C57BL/6J wildtype (WT) mice were obtained from the Jackson Laboratory (Bar Harbor, ME, USA). Mice were fed a normal (CON) or western diet (WD; 42\% calories from fat; TD.88137, Envigo) and had free access to water. Mice were housed in a $12 \mathrm{~h}$ light/12 h dark cycle. Body weight was measured every week.

Glucose tolerance. Intraperitoneal glucose tolerance testing was performed in fasted mice. Briefly, mice were given glucose [2 $\mathrm{g} / \mathrm{kg}$ body weight, intraperitoneal (i.p.)], and tail vein blood glucose was measured using a blood glucose meter (Roche Diagnostics, Mannheim, Germany) at baseline and at 30, 60, 90, and $120 \mathrm{~min}$ post-injection. Glucose tolerance was evaluated by areas under the curve (AUC).

Hydroxyproline assay. Renal collagen content was measured using the hydroxyproline assay. The renal samples were prepared as previously described (26). The hydroxyproline content was detected using a colorimetric assay kit (Sigma-Aldrich, St. Louis, MO, USA). The amount of hydroxyproline per milligram of dry kidney tissue was calculated, assuming that collagen contains an average of $13.5 \%$ hydroxyproline (26).

Immunohistochemistry. Three- $\mu$ m-thick paraffin sections of the kidney were deparaffinized and rehydrated. The sections were treated with $3 \%$ hydrogen peroxide, blocked with 5\% normal donkey serum, and incubated with antibodies against F4/80 (1:100; Serotec, Oxford, UK), phosphorylated Smad2/3 (1:200, Santa Cruz Biotechnology, Santa Cruz, CA, USA), and phosphorylated Smad1 (1:200, Santa Cruz Biotechnology) overnight at $4^{\circ} \mathrm{C}$. Then, the sections were incubated with HRP-labeled secondary antibodies (Vector Laboratories, Burlingame, CA, USA) and visualized using the substrate fast red or 3,3'-diaminobenzidine (Vector Laboratories). F4/80-positive cells per square millimeter were quantified in the cortex and outer medulla using fifteen random fields (Olympus BX41 model, Olympus Optical Co. Ltd, Tokyo, Japan; Olympus MicroSuiteTM-Basic software, Olympus Soft Imaging Solutions GmbH, Münster, Germany). Periodic acid-Schiff stain (PAS, Abcam, Cambridge, MA, USA) staining was also performed.
Determination of renal malondialdehyde (MDA) and cytokines. Kidney slices $(0.5 \mathrm{~mm})$ were transferred immediately to chambers containing RPMI 1640 culture medium with 5\% BSA and saturated with $95 \% \mathrm{O}_{2}-5 \% \mathrm{CO}_{2}$ at $37^{\circ} \mathrm{C}$. After $1 \mathrm{~h}$ equilibration, lactate dehydrogenase $(\mathrm{LDH})$ concentrations were measured to make sure the tissue was alive. Then the kidney slices were saturated with $95 \%$ $\mathrm{O}_{2}-5 \% \mathrm{CO}_{2}$ at $37^{\circ} \mathrm{C}$ in control groups (con) or saturated with $99 \%$ $\mathrm{N}_{2}$ in ischemic groups (I). Subsequently, the kidney slices were collected and immediately frozen at $-80^{\circ} \mathrm{C}$ until measurements would be taken (27). Monocyte chemoattractant protein-1 (MCP-1), TNF- $\alpha$, and interleukin (IL)-6 secretions from the kidney tissues were measured using ELISA kits (eBioscience, San Diego, CA, USA). Malondialdehyde (MDA) content was determined using a Thiobarbituric Acid Reactive Substances (TBARS) kit (Cayman chemical, Ann Arbor, MI, USA).

Renal ischemia/reperfusion model $(28,29)$. After 23 weeks of dietary intervention, mice anesthetized with ketamine $(85 \mathrm{mg} / \mathrm{kg}$, i.p.) and xylazine $(5 \mathrm{mg} / \mathrm{kg}$, i.p.) were placed on a heating pad. Mice were infused with $1 \%$ bovine serum albumin in saline solution at a rate of $2 \mathrm{ml} / 100 \mathrm{~g} / \mathrm{h}$ during the experiment (30). The surface of the kidney was gently flushed by $0.9 \%$ saline solution. Both renal vessels were then tightened by a microaneurysm clamp (Fine Science Tools, Foster City, CA, USA) to occlude the blood flow for $40 \mathrm{~min}$ (ischemic phase). During the ischemic period evidence of clamping was confirmed by the dark color of ischemic kidneys. The clamp was subsequently released to restore blood perfusion to the ischemic kidney for $3 \mathrm{~h}$. Sham surgery consisted of the same surgical procedure except that clamps were not applied. To determine the role of endogenous CGRP during I/R, CGRP8-37, a CGRP antagonist, was given $[20 \mathrm{nmol} / \mathrm{kg} / \mathrm{min}$, by intravenous $(i . v)$. injection during the renal $\mathrm{I} / \mathrm{R}$ period. Urine, blood, and kidney samples were obtained at the end of the experiment.

$N F-k B$ p65 assay. Nuclear fraction of the kidney was extracted using a Nuclear Extract Kit (Active Motif, Carlsbad, CA, USA). The binding activity of free NF-kB p65 in the nuclear extracts was determined using the TransAM NF-kB p65 assay kit (Active Motif). Absorbance at $450 \mathrm{~nm}$ was measured using a microplate reader (BioTek Instruments, Winooski, VT, USA).

Renal function assessment. Plasma creatinine and blood urea nitrogen were measured using a Creatinine Colorimetric Assay Kit and a Urea Colorimetric Assay Kit (Biovision, Milpitas, CA, USA). Urinary LDH was measured using an LDH Colorimetric Assay Kit (Biovision).

Statistical analysis. Data are expressed as mean \pm SEM. Differences among groups were analyzed by one-way ANOVA analysis followed by the post-hoc Tukey HSD test. Differences between two groups were determined using the $t$-test. A $p$-value less than 0.05 was considered statistically significant.

\section{Results}

Glucose intolerance is exacerbated in TRPVI knockout mice. After fed with a normal diet for 23 weeks, the body weight (BW) was similar between the WT and the TRPV $1^{-1-}$ mice (WT BW=30.5 \pm 5.4 g vs. TRPV $1^{-/-} \quad \mathrm{BW}=32.5 \pm 4.2 \mathrm{~g}$ ); 
A

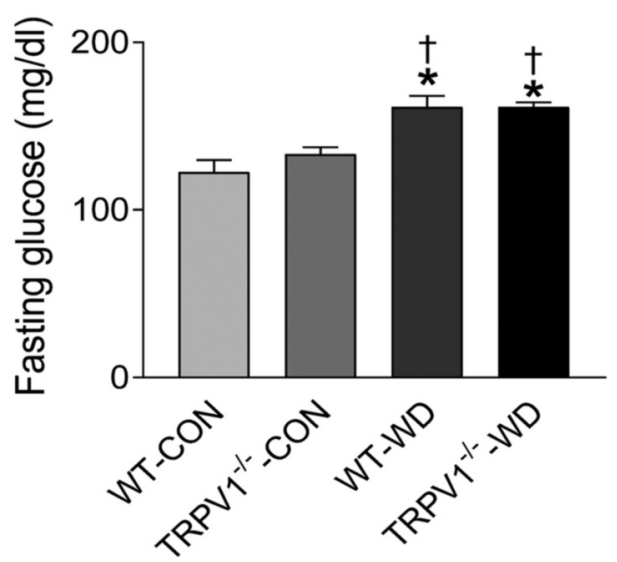

B

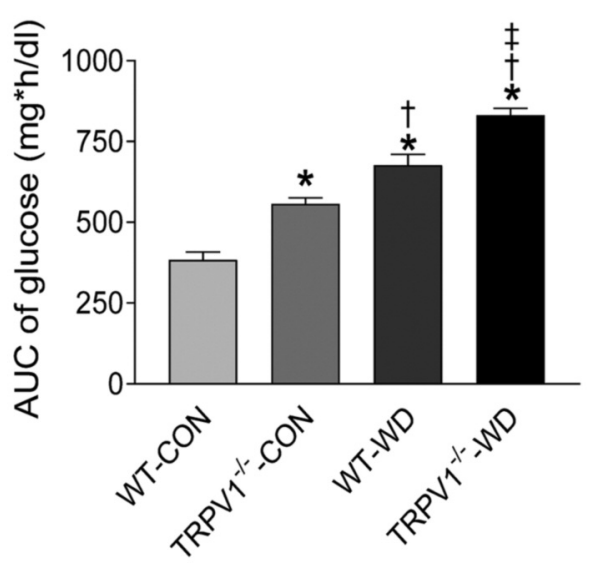

Figure 1. TRPVI knockout exacerbates WD-induced glucose intolerance. (A) Plasma glucose levels before and after glucose injection (2g/kg) were measured in WT and TRPVI-l- mice fed normal (CON) or western diet (WD) for 23 weeks. (B) Mean area under the curve (AUC) of glucose was calculated. Values are mean \pm SEM $(n=6)$. ${ }^{*} p<0.05 \mathrm{vs}$. WT-CON; ${ }^{\dagger} p<0.05 \mathrm{vs}$. TRPV1-l-CON; ${ }^{*} p<0.05 v s$. WT-WD.

A

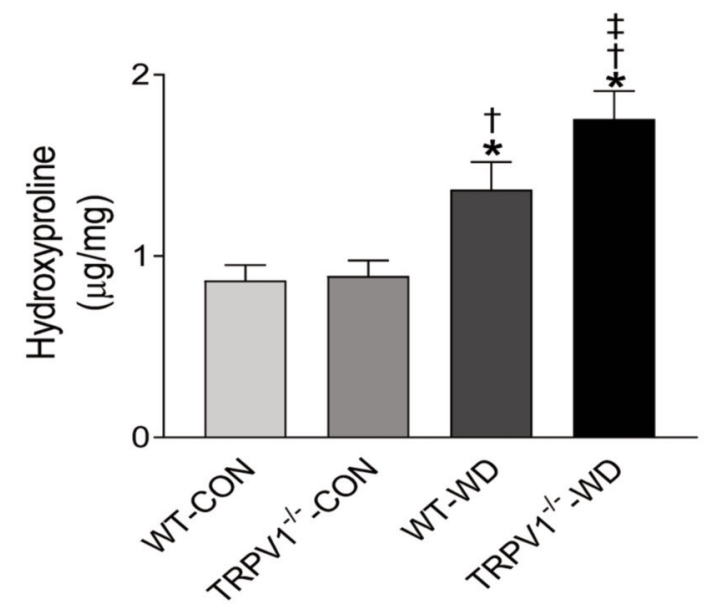

B

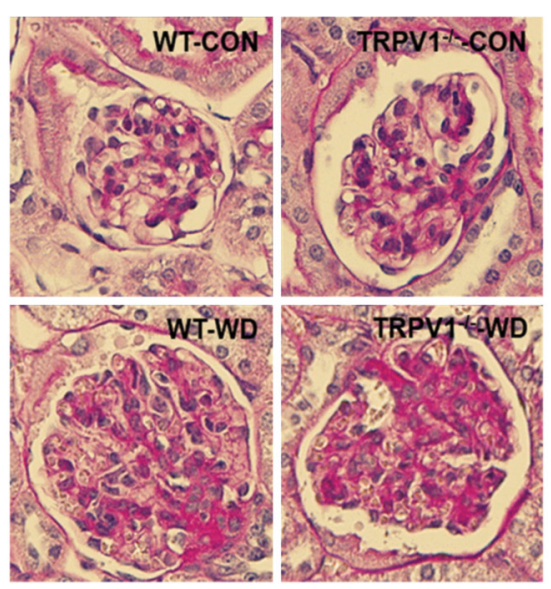

Figure 2. Deletion of TRPV1 exacerbates WD-induced renal collagen deposition. (A) The amount of hydroxyproline per milligram of dry kidney tissue in WT and TRPV1-l- mice fed normal (CON) or western diet (WD). Values are mean \pm SEM $(n=6)$. (B) Periodic acid-Schiff (PAS)-stained glomeruli. Magnification: 400x. *p<0.05 vs. WT-CON; ${ }^{\dagger} p<0.05$ vs. TRPV1-1-_CON; ${ }^{\star} p<0.05 v s$. WT-WD.

however, the weight gain was significantly increased by WD intake in both strains $(p<0.01)$ with no difference between WT and TRPV $1^{-/-}$mice (WT BW=46.5 $\pm 7.8 \mathrm{~g} v s$. TRPV $1^{-/-}$ $\mathrm{BW}=43.2 \pm 7.7 \mathrm{~g}$ ). Fasting glucose levels were significantly elevated by WD intake in both strains $(p<0.01)$ compared to normal diet, with no difference between WT-WD and TRPV1 ${ }^{-/}$-WD mice (Figure 1). Glucose tolerance was significantly impaired in both strains with WD intake (Figure $1, p<0.01)$, reflected by increased AUC, most prominent in TRPV1 ${ }^{-/}-$WD mice (Figure 1).
TRPV1 gene deletion exacerbates WD-induced renal collagen deposition and macrophage infiltration. WD intake increased collagen deposition in the kidneys of WT and TRPV1 ${ }^{-/-}$mice, reflected by increased levels of hydroxyproline, with greater collagen content in the TRPV1 ${ }^{-l}$-WD mice (Figure 2A). PAS-staining also showed enhanced extracellular matrix (ECM) deposition in the glomeruli from mice with WD intake (Figure 2B). Renal macrophages were identified as F4/80-positive cells. TRPV1 ${ }^{-/-}$-WD mice showed a significant increase in the 
A

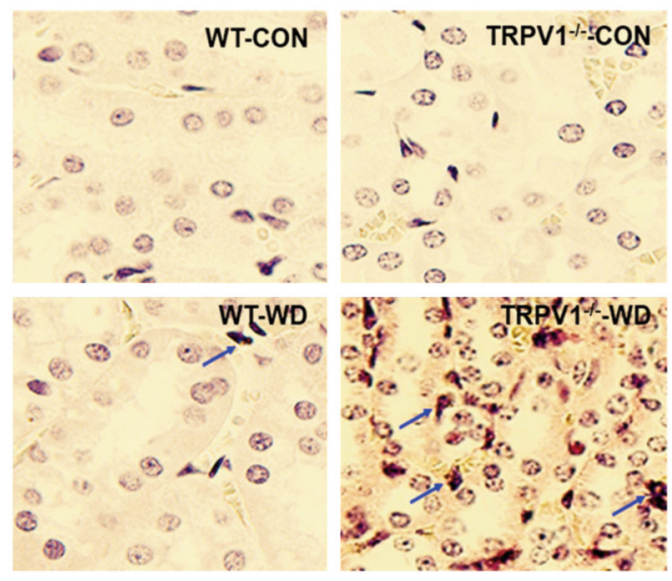

B

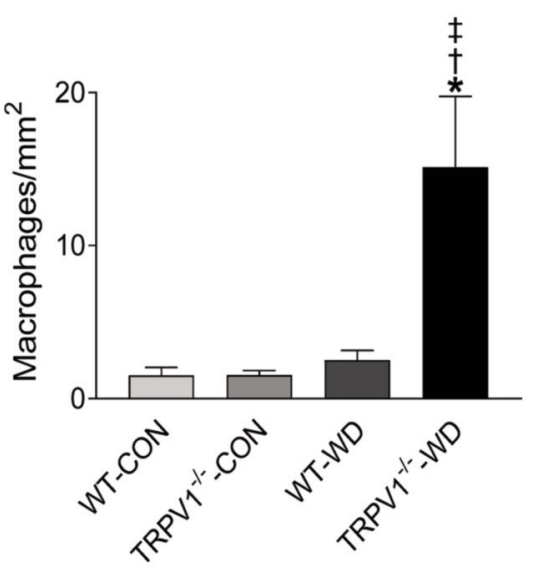

Figure 3. Deletion of TRPV1 exacerbates WD-induced renal macrophage infiltrations. (A) Immunostaining of F4/80-positive cells (macrophages in red) in the kidney from WT and TRPV1-l- mice with normal diet (CON) or western diet (WD) intake for 23 weeks. Arrows: F4/80-positive cells. Magnification: 400x. (B) Quantification of macrophages was expressed as cells per square millimeter. Values are mean \pm SEM ( $n=4-5)$. ${ }^{2}<0.05$ vs. WT-CON; ${ }^{\dagger} p<0.05$ vs. TRPV1-l--CON; ${ }^{\dagger} p<0.05$ vs. WT-WD.

number of F4/80-positive cells in their kidney compared to that WT-WD mice $(p<0.05$, Figure 3$)$.

Exacerbated WD-induced renal inflammation in TRPVI knockout mice. WD intake enhanced MDA, IL-6, and MCP-1 levels in the kidney of both TRPV $1^{-/-}$and WT mice (Figure 4). Incubation under hypoxic conditions ( $\left(99 \% \quad \mathrm{~N}_{2}\right)$ significantly increased renal MDA, IL-6, and MCP-1 levels in kidney sections compared to sections exposed to $95 \% \mathrm{O}_{2}-5 \%$ $\mathrm{CO}_{2}$, while WD enhanced the hypoxia-induced MDA, IL-6, and MCP-1 levels in both strains with a more prominent effect in TRPV1 ${ }^{-/}$-WD mice (Figure 4). Kidney sections from WTCON mice pretreated with CGRP8-37 (CGRP antagonist) significantly increased renal MDA, IL-6, and MCP-1 levels compared to WT-CON with ischemia alone (Figure 4).

Exacerbated expression of WD-induced renal p-Smad1, $p$ Smad2/3, and p65-NF-kB in TRPV1 knockout mice. Immunohistochemical staining demonstrated that renal I/R increased renal p-Smad1-positive cells with a greater intensity in TRPV1 ${ }^{-/}-\mathrm{WD}-\mathrm{I} / \mathrm{R}$ mice (Figures 5A and B). Similarly, renal I/R increased renal p-Smad2/3-positive cells with a greater intensity in TRPV1 $1^{-/}-\mathrm{WD}-\mathrm{I} / \mathrm{R}$ mice (Figures $5 \mathrm{C}$ and $\mathrm{D})$. WD intake significantly increased renal NF-kB p65 levels in WT and TRPV1 ${ }^{-1-}$ mice, which were exacerbated in TRPV $1^{-/-}$mice $(p<0.05$, Figure $5 \mathrm{E})$. Renal I/R injury significantly increased NF-kB p65 levels, with TRPV $1^{-1-}$-WD-I/R mice expressing the highest NF-KB p65 levels compared to WT-WD-I/R mice and both strains with normal diet intake at the same time point after $\mathrm{I} / \mathrm{R}$ injury (Figure 5E).
TRPVI gene deletion exacerbates renal injury in obese mice. Increased urinary $\mathrm{LDH}$ release during postischemic reperfusion is a marker of ischemic injury (31). Baseline LDH levels had no significant difference between TRPV1${ }^{-}$and WT mice (data not shown). WD intake increased LDH levels in both strains after I/R, with a significantly higher increase in TRPV $1^{-/}$mice (Figure 6A). After renal I/R, plasma levels of urea and creatinine were significantly higher in both strains with WD intake; with TRPV $1^{-/}$WD mice expressing significantly higher levels compared to WT-WD mice (Figures 6B and C). These results demonstrate that I/Rinduced renal dysfunction is exacerbated by both WD intake and TRPV1 ablation. To determine the role of endogenous CGRP during I/R, we assessed the effect of its inhibitor, CGRP8-37 on plasma creatinine, urea and urine LDH levels, and saw that these are increased In CGRP8-37 treated WT mice compared to WT mice without CGRP8-37 treatment (Figure 6).

\section{Discussion}

The purpose of this study was to examine the role of TRPV1 in renal inflammatory responses, collagen deposition, and renal dysfunction in diet-induced obese mice with renal I/R. WD intake has been associated with an increased incidence of chronic kidney disease and enhanced renal I/R injury, which is related to chronic activation of inflammation, increased oxidative stress, and development of glomerulosclerosis $(32,33)$. The present study found that WD intake significantly increased TNF- $\alpha$, IL-6, and MCP-1 in the kidneys of both WT and TRPV $1^{-/}$mice, possibly as 
A

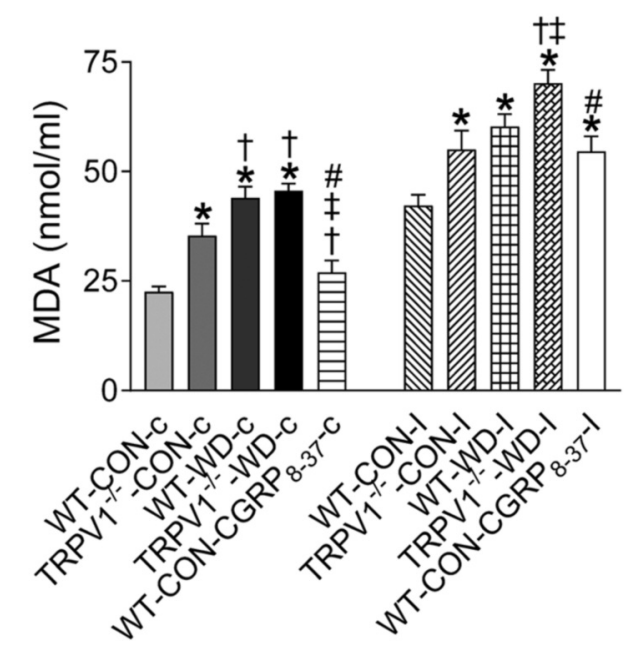

B
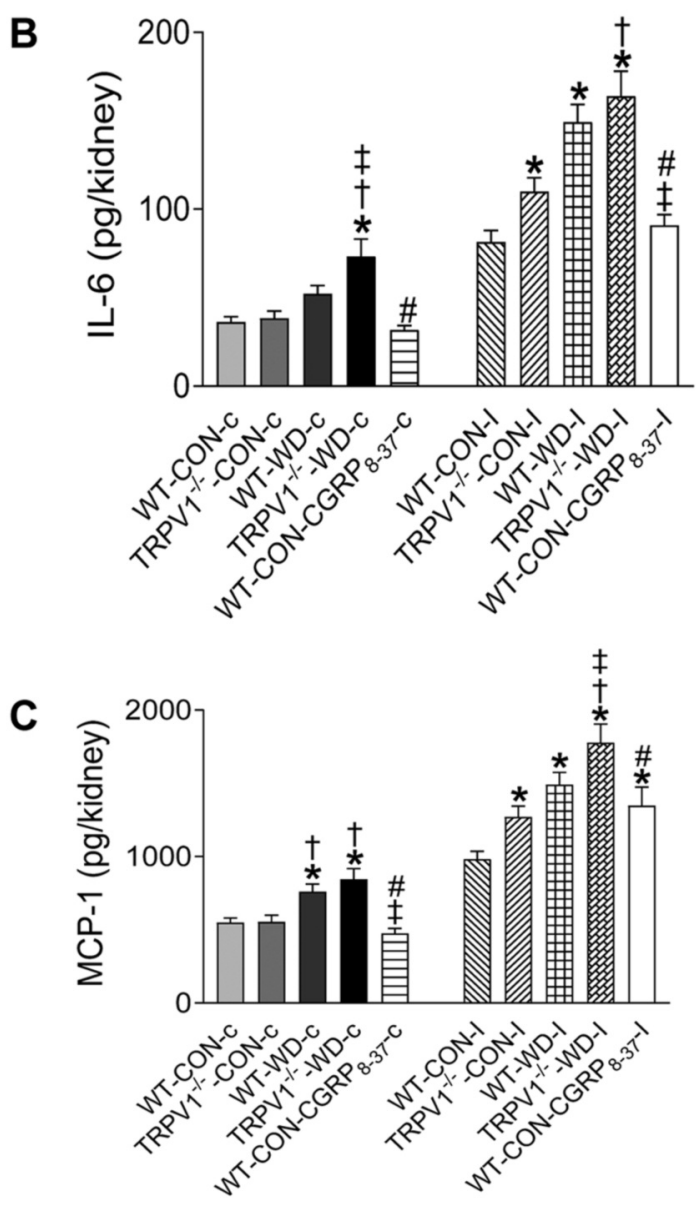

Figure 4. WD-induced renal inflammation is exacerbated in TRPVI knockout mice. Kidney slices from WT and TRPV1-I- mice fed with western (WD) or normal (CON) diet for 23 weeks were subjected to ischemia ( $I$, incubated with $\left.99 \% N_{2}\right)$ or a control condition $(C$, incubated with $95 \% \mathrm{O}_{2}-5 \% \mathrm{CO}_{2}$ ). Malondialdehyde (MDA, A), IL-6 (B), and MCP-1 (C) levels in the kidneys were measured. Values are mean $\pm S E M(n=7-8) .{ }^{*} p<0.05 v s$. WT-CON-c; ${ }^{\dagger} p<0.05$ vs. TRPVI ${ }^{-1-}$ CON-c; ${ }^{*} p<0.05$ vs. WT-WD-c; ${ }^{\#} p<0.05$ vs. TRPVI-l- $W D$. a result of hyperglycemia induced by WD intake. WD intake significantly increased fasting glucose levels in both strains, with no difference between TRPV $1^{-1-}$ and WT mice with WD intake. WD intake impaired glucose tolerance in both strains with an exacerbation in TRPV $1^{-/}$mice, possibly contributing to increased risk of cardiovascular disease (34). Oxidative damage induced by hyperglycemia is critical for tissue injury (35). Hyperglycemia induces oxidative stress possibly via NF-kB p65 activation and increase of TNF-a, IL-6, and MCP-1 (36). High glucose levels induce TNF- $\alpha$ and MCP-1 secretion and stimulate collagen synthesis through ROS, NF-kB, and the Smad pathway $(37,38)$. Consistently, our data showed that WD intake increased MDA levels, a marker of lipid peroxidation, enhanced MCP1, TNF-a, and IL-6 in both TRPV1 ${ }^{-/}$and WT mice. NF-kB is a central mediator of inflammatory and oxidative responses (39). WD intake increased NF-kB P65 in WT and TRPV $1^{-/-}$mice, which were exacerbated in TRPV $1^{-/-}$-WD mice. These data indicate that WD intake can cause chronic renal inflammatory responses in WT and TRPV $1^{-/-}$mice and that TRPV1 ablation enhances the monocyte/macrophage infiltration, accompanied by an increase in NF-kB P65 activity and release of TNF-a, IL-6, and MCP-1 from the kidney.

WD intake enhanced renal collagen deposition and macrophage infiltration, which were exacerbated in TRPV $1^{-/-}$ mice. In these mice, activation of the Smad pathway plays a key role towards the enhancement of renal fibrosis and inflammation. Smad proteins are related to renal development, cell proliferation, cell growth, and apoptosis (40). Smad1 is highly expressed in diabetic nephropathy and is related to its initiation and progression and plays a role in the development of glomerulosclerosis (15). Heart I/R may lead to enhancement of bone morphogenetic protein-4 expression and Smad1/5/8 phosphorylation in the heart, which is related to an increase in apoptosis and proinflammatory gene expression (41). In contrast, other studies have shown that Smad1 protects cardiomyocytes from $\mathrm{I} / \mathrm{R}$ injury (42). In the present study, we evaluated the $\mathrm{p}$ Smad1 expression changes in WT and TRPV1 $1^{-/}$mice with long term WD intake and as acute renal I/R models. Our data demonstrated that $\mathrm{p}$-Smad1-positive cells are expressed in tubules and interstitial infiltrating cells in TRPV1 $1^{-/}$WD mice and that renal I/R increased the renal $\mathrm{p}-\mathrm{Smad} 1$ expression in the kidney of these mice, also characterized by exacerbated renal inflammatory responses and renal dysfunction. The TGF- $\beta /$ Smad2/3 signal pathway plays a role in the pathogenesis of obesity and type 2 diabetes, with increased levels of $p$-smad2/3 and fibrosis present in diabetic nephropathy (43). Smad3 deficiency or inhibition protects against insulin resistance and obesity induced by high-fat diet (18). We have previously reported that activation of $S \operatorname{mad} 2 / 3$ contributes to renal fibrosis, and TRPV1 plays a role in the 


\section{A}

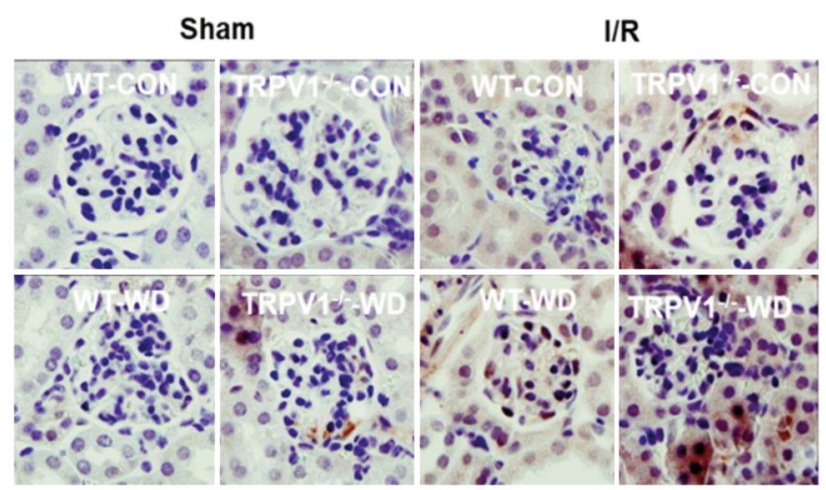

\section{C}

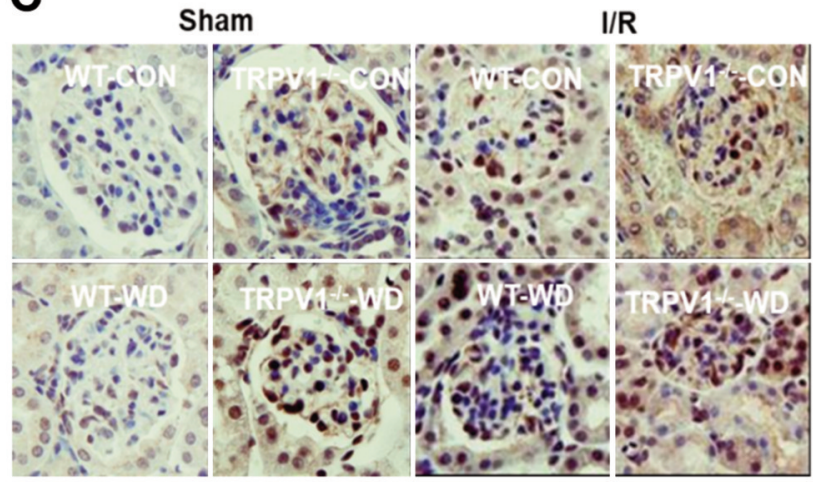

B

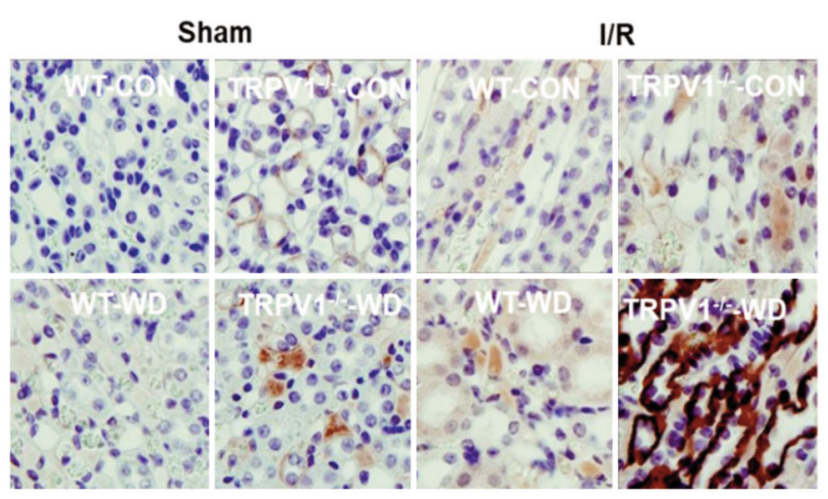

D

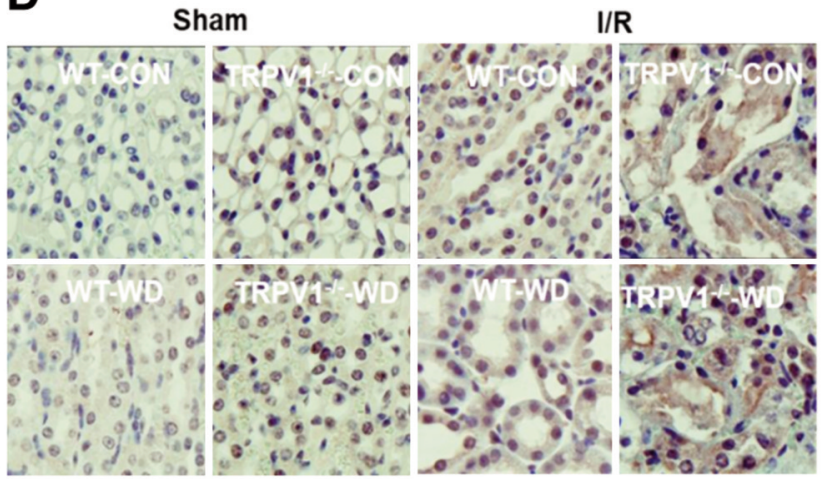

$\mathbf{E}$

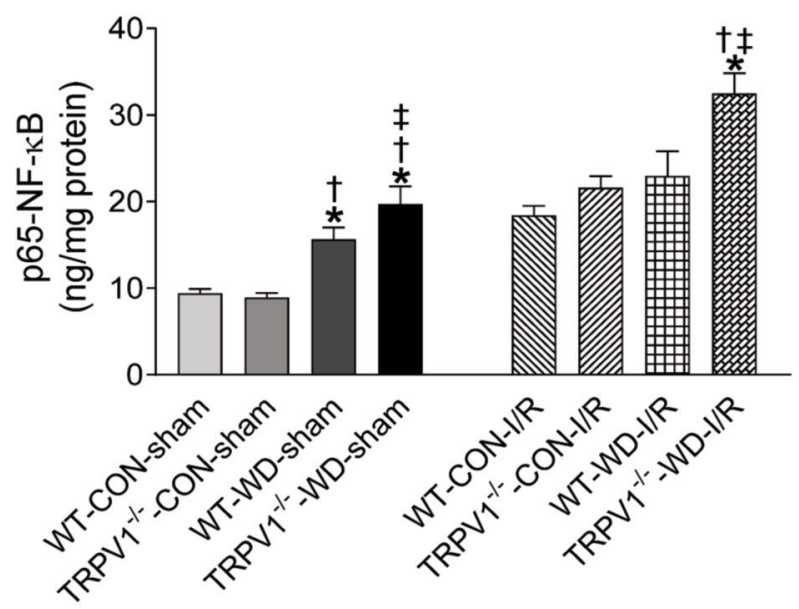

Figure 5. TRPV1 deletion exacerbates WD-induced renal $p$-Smad1, $p$-Smad2/3, and p65-NF-KB expression. WT and TRPV1 ${ }^{-/-}$mice fed with western $(W D)$ or normal (CON) diet for 23 weeks were subjected to sham operation or ischemia $(40 \mathrm{~min})$ and reperfusion $(3 \mathrm{~h})(\mathrm{I} / \mathrm{R})$. Immunohistochemistry of p-Smad1 in the glomeruli (A) and tubulointerstitial tissue $(B)$ and of $p$-Smad2/3 in the glomeruli $(C)$ and tubulointerstitial tissue (D). Magnification: 400x. (E) Renal p65-NF-kB. * ${ }^{*}<0.05$ vs. WT-CON-IR; ${ }^{\dagger} p<0.05$ vs. TRPV1-/-CON-IR; ${ }^{\ddagger} p<0.05$ vs. WT-WD-IR.

protection against renal fibrosis by inhibiting TGF- $\beta / \mathrm{Smad} 2 / 3$ signaling in DOCA-salt hypertensive mice (44). In the present study, we showed that p-Smad2/3-positive cells were expressed in the glomeruli, tubules, and in interstitial infiltrating cells of TRPV1 ${ }^{-/-}$WD mice. However, p-smad1positive cells were not found in the glomeruli of WT and TRPV1 $1^{-/}$mice with WD intake. These data collectively indicate that $\mathrm{p}-\mathrm{Smad} 2 / 3$, but not $\mathrm{p}$-Smad1, plays a key role in 
A

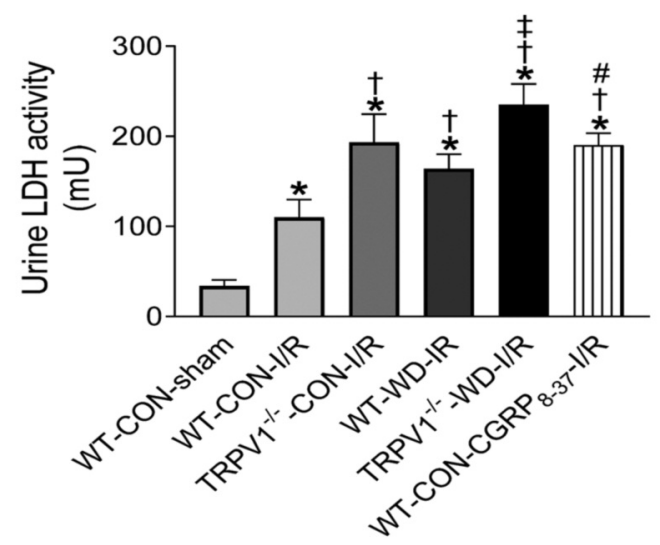

B

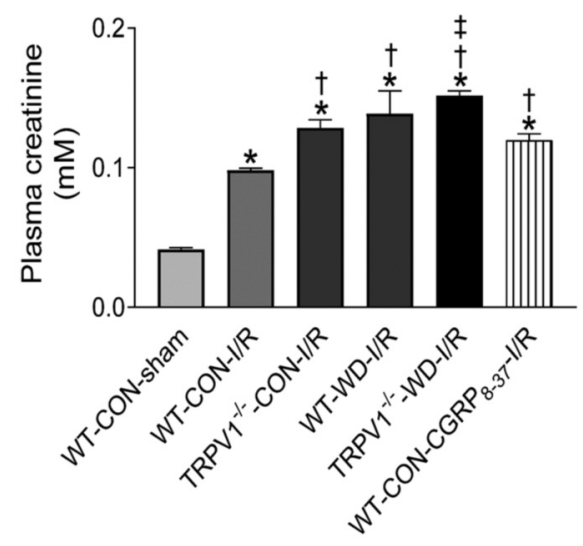

c

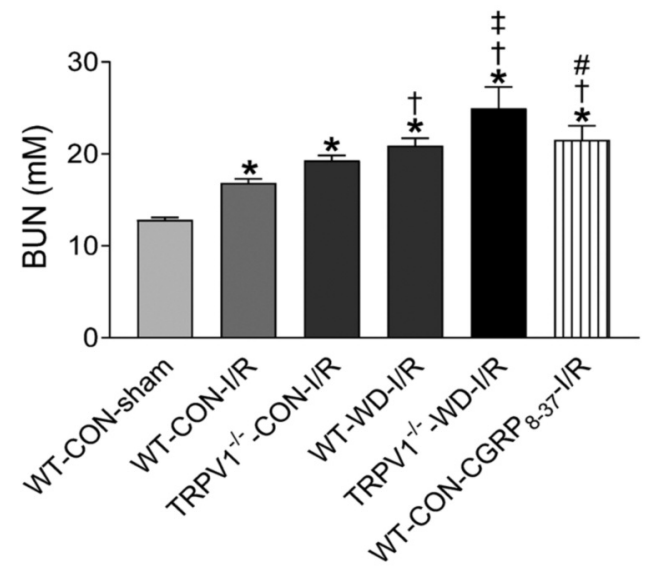

Figure 6. Effects of CGRP antagonism on renal function after I/R injury. After 23 weeks of western (WD) or normal diet (CON) intake, the mice were subjected to ischemia $(40 \mathrm{~min})$ and reperfusion $(3 \mathrm{~h})(I / R)$ or a sham operation. Urinary lactate dehydrogenase ( $L D H, A)$, plasma creatinine $(B)$, and blood urea nitrogen $(C)$ levels were measured. Values are mean \pm SEM $(n=5-6) .{ }^{*} p<0.05$ vs. WT-CON-sham; ${ }^{\dagger} p<0.05$ vs. WTCON-I/R; ${ }^{*} p<0.05$ vs. WT-WD-I/R; ${ }^{*} p<0.05$ vs. TRPVI-I-WD-I/R.

renal fibrosis in the TRPV1 knockout with WD intake, and suggest that TRPV1 ablation likely plays a role in the elevation of $\mathrm{p}-\mathrm{Smad} 1$ and $\mathrm{p}-\mathrm{Smad} 2 / 3$ signaling pathway during renal I/R injury. In TRPV $1^{-/}$mice WD intake resulted in enhanced renal collagen deposition and ECM protein expression in the glomeruli, which

Renal hypoxia is a characteristic of diabetic kidney disease $(45,46)$, responsible for inducing inflammatory gene expression (47). Our data provide experimental evidence that hypoxia increases renal oxidative stress and increases the levels of proinflammatory cytokines and chemokines. Hypoxia increases p-Smad2/3 causing increased levels of Smad3transcriptional activity, and subsequently leading to increased TGF- $\beta$ gene expression (48).

ROS plays a critical role in TNF- $\alpha$-induced insulin resistance in adipocytes (49). Studies have shown that loss of TRPV1-positive sensory nerves leads to increased TNF$\alpha$ levels (50) and treatment with endotoxin in TRPV $1^{-/-}$ mice increases cytokine levels in peritoneal fluid (24), supporting the notion that chronic TRPV1 activation protects against inflammatory response. Mice on WD show enhanced tissue injury and inflammatory responses with or without I/R injury, as well as exacerbated renal damage when the TRPV1 gene is ablated.

WD intake and TRPV1 ablation enhanced the I/Rinduced renal dysfunction, which may have resulted from the impairment of CGRP, causing it to release an excessive amount of free radicals (10). It has been reported that CGRP is important for neuroendocrine-immune interactions (51). CGRP can inhibit IL-1 $\beta$-induced endogenous MCP-1 secretion in type II alveolar epithelial cells (52). CGRP also inhibits hydrogen peroxide production in macrophages (53) and endotoxin-induced secretion of cytokines $(54,55)$. It also suppresses antigen presentation, phagocytosis, DNA synthesis and differentiation of macrophages $(55,56)$. Indeed, inflammation is enhanced in CGRP knockout mice (57). Consistently, our data show that CGRP8-37, a CGRP antagonist, increased renal MDA levels as well as the release of TNF- $\alpha$ and MCP-1 from the kidney after ischemia treatment in WT-CON mice. These data indicate that CGRP inhibits the inflammatory response from renal ischemia, resulting in improved recovery of renal function after I/R.

In conclusion, these data indicate that preserving TRPV1 expression and function may prevent renal injury in dietinduced obese mice possibly via alleviating their inflammatory responses.

\section{Conflicts of Interest}

There are no conflicts of interest to declare regarding this study.

\section{Authors' Contributions}

DHW was involved in conception and design of the study. BZ and DHW were involved in data collection, analysis and interpretation, as well as manuscript writing. SM revised the manuscript and BZ, SM, DHW were involved in the final approval of manuscript. 


\section{Acknowledgements}

This work was supported by grants from the National Institutes of Health (HL-57853, HL-73287, and DK67620).

\section{References}

1 Caterina MJ, Leffler A, Malmberg AB, Martin WJ, Trafton J, Petersen-Zeitz KR, Koltzenburg M, Basbaum AI and Julius D: Impaired nociception and pain sensation in mice lacking the capsaicin receptor. Science 288(5464): 306-313, 2000. PMID: 10764638. DOI: $10.1126 /$ science.288.5464.306

2 Julius D and Basbaum AI: Molecular mechanisms of nociception. Nature 413: 203-210, 2001. PMID: 11557989. DOI: $10.1038 / 35093019$.

3 Sexton A, McDonald M, Cayla C, Thiemermann C and Ahluwalia A: 12-Lipoxygenase-derived eicosanoids protect against myocardial ischemia/reperfusion injury via activation of neuronal TRPV1. Faseb J 21: 2695-2703, 2007. PMID: 17470568. DOI: $10.1096 /$ fj.06-7828com

4 Zhong B, Ma S and Wang DH: TRPV1 Mediates glucose-induced insulin secretion through releasing neuropeptides. In Vivo 33: 1431-1437, 2019. PMID: 31471389. DOI: 10.21873/invivo.11621

5 Duan JX, Zhou Y, Zhou AY, Guan XX, Liu T, Yang HH, Xie H and Chen P: Calcitonin gene-related peptide exerts antiinflammatory property through regulating murine macrophages polarization in vitro. Mol Immunol 91: 105-113, 2017. PMID: 28892747. DOI: 10.1016/j.molimm.2017.08.020

6 Chai SY, Christopoulos G, Cooper ME and Sexton PM: Characterization of binding sites for amylin, calcitonin, and CGRP in primate kidney. Am J Physiol 274: F51-62, 1998. PMID: 9458823. DOI: 10.1152/ajprenal.1998.274.1.F51

7 Huang W, Rubinstein J, Prieto AR, Thang LV and Wang DH: Transient receptor potential vanilloid gene deletion exacerbates inflammation and atypical cardiac remodeling after myocardial infarction. Hypertension 53: 243-250, 2009. PMID: 19114647. DOI: 10.1161/HYPERTENSIONAHA.108.118349

8 Yu SQ, Ma S and Wang DH: Activation of TRPV1 prevents saltinduced kidney damage and hypertension after renal ischemiareperfusion injury in rats. Kidney Blood Press Res 43: 12851296, 2018. PMID: 30078015. DOI: 10.1159/000492412

9 Zhong B, Ma S and Wang DH: Protective effects of TRPV1 activation against cardiac ischemia/reperfusion injury is blunted by diet-induced obesity. Cardiovasc Hematol Disord Drug Targets, 2019. PMID: 31513001. DOI: 10.2174/ 1871529X19666190912152041

10 Zhong B, Ma S and Wang DH: TRPV1 protects renal ischemiareperfusion injury in diet-induced obese mice by enhancing CGRP release and increasing renal blood flow. PeerJ 7: e6505, 2019. PMID: 30834186. DOI: 10.7717/peerj.6505

11 Shi Q, Vandeberg JF, Jett C, Rice K, Leland MM, Talley L, Kushwaha RS, Rainwater DL, Vandeberg JL and Wang XL: Arterial endothelial dysfunction in baboons fed a highcholesterol, high-fat diet. Am J Clin Nutr 82: 751-759, 2005. PMID: 16210703. DOI: 10.1093/ajcn/82.4.751

12 Kim F, Pham M, Luttrell I, Bannerman DD, Tupper J, Thaler J, Hawn TR, Raines EW and Schwartz MW: Toll-like receptor-4 mediates vascular inflammation and insulin resistance in dietinduced obesity. Circ Res 100: 1589-1596, 2007. PMID: 17478729. DOI: 10.1161/CIRCRESAHA.106.142851
13 Kern L, Mittenbuhler MJ, Vesting AJ, Ostermann AL, Wunderlich CM and Wunderlich FT: Obesity-induced TNFalpha and IL-6 signaling: The missing link between obesity and inflammation-driven liver and colorectal cancers. Cancers (Basel) 11: 24, 2019. PMID: 30591653. DOI: 10.3390/ cancers 11010024

14 Zhang X, Liu D, He Y, Lou K, Zheng D and Han W: Branched chain amino acids protects rat mesangial cells from high glucose by modulating TGF-beta1 and BMP-7. Diabetes Metab Syndr Obes 12: 2433-2440, 2019. PMID: 31819569. DOI: $10.2147 /$ DMSO.S221642

15 Abe H, Matsubara T, Iehara N, Nagai K, Takahashi T, Arai H, Kita T, and Doi T: Type IV collagen is transcriptionally regulated by Smad1 under advanced glycation end product (AGE) stimulation. J Biol Chem 279: 14201-14206, 2004. PMID: 14732718. DOI: 10.1074/jbc.M310427200

16 Mima A, Abe H, Nagai K, Arai H, Matsubara T, Araki M, Torikoshi K, Tominaga T, Iehara N, Fukatsu A, Kita T and Doi $\mathrm{T}$ : Activation of Src mediates PDGF-induced Smad1 phosphorylation and contributes to the progression of glomerulosclerosis in glomerulonephritis. PLoS One 6: e17929. PMID: 21445358. DOI: 10.1371/journal.pone.0017929

17 Hong SK, Choo EH, Ihm SH, Chang K and Seung KB: Dipeptidyl peptidase 4 inhibitor attenuates obesity-induced myocardial fibrosis by inhibiting transforming growth factorbetal and Smad2/3 pathways in high-fat diet-induced obesity rat model. Metabolism 76: 42-55, 2017. PMID: 28987239. DOI: 10.1016/j.metabol.2017.07.007

18 Tan CK, Leuenberger N, Tan MJ, Yan YW, Chen Y, Kambadur $\mathrm{R}$, Wahli W and Tan NS: Smad3 deficiency in mice protects against insulin resistance and obesity induced by a high-fat diet. Diabetes 60: 464-476, 2011. PMID: 21270259. DOI: 10.2337/ db10-0801

19 Liano F and Pascual J: Epidemiology of acute renal failure: a prospective, multicenter, community-based study. Madrid Acute Renal Failure Study Group. Kidney Int 50: 811-818, 1996. PMID: 8872955. DOI: 10.1038/ki.1996.380

20 Meldrum KK, Meldrum DR, Meng X, Ao L and Harken AH: TNF-alpha-dependent bilateral renal injury is induced by unilateral renal ischemia-reperfusion. Am J Physiol Heart Circ Physiol 282: H540-546, 2002. PMID: 11788401. DOI: 10.1152/ ajpheart.00072.2001

21 Kelly KJ, Burford JL and Dominguez JH: Postischemic inflammatory syndrome: a critical mechanism of progression in diabetic nephropathy. Am J Physiol Renal Physiol 297: F923931, 2009. PMID: 19656916. DOI: 10.1152/ajprenal.00205.2009

22 Davidson EP, Coppey LJ, Calcutt NA, Oltman CL and Yorek MA: Diet-induced obesity in Sprague-Dawley rats causes microvascular and neural dysfunction. Diabetes Metab Res Rev 26: 306-318. PMID: 20503263. DOI: 10.1002/dmrr.1088

23 Haddock RE and Hill CE: Sympathetic overdrive in obesity involves purinergic hyperactivity in the resistance vasculature. J Physiol 589: 3289-3307. PMID: 21576274.

24 Clark N, Keeble J, Fernandes ES, Starr A, Liang L, Sugden D, de Winter P and Brain SD: The transient receptor potential vanilloid 1 (TRPV1) receptor protects against the onset of sepsis after endotoxin. Faseb J 21: 3747-3755, 2007. PMID: 17601984. DOI: $10.1096 / f j .06-7460 \mathrm{com}$

25 Helyes Z, Elekes K, Nemeth J, Pozsgai G, Sandor K, Kereskai L, Borzsei R, Pinter E, Szabo A and Szolcsanyi J: Role of 
transient receptor potential vanilloid 1 receptors in endotoxininduced airway inflammation in the mouse. Am J Physiol Lung Cell Mol Physiol 292: L1173-1181, 2007. PMID: 17237150. DOI: 10.1152/ajplung.00406.2006

26 Peng H, Carretero OA, Alfie ME, Masura JA and Rhaleb NE: Effects of angiotensin-converting enzyme inhibitor and angiotensin type 1 receptor antagonist in deoxycorticosterone acetate-salt hypertensive mice lacking Ren-2 gene. Hypertension 37: 974-980, 2001. PMID: 11244026. DOI: 10.1161/01.hyp.37.3.974

27 Jeron A, Straub RH, Kaiser T, Riegger GA and Muders F: Systemic immunosuppression fails to suppress cardiac cytokine induction in pressure overload hypertrophy in rats. Immunobiology 205: 51-60, 2002. PMID: 11999344. DOI: 10.1078/0171-2985-00110

28 Shi H, Patschan D, Epstein T, Goligorsky MS and Winaver J: Delayed recovery of renal regional blood flow in diabetic mice subjected to acute ischemic kidney injury. Am J Physiol Renal Physiol 293: F1512-1517, 2007. PMID: 17881464. DOI: 10.1152/ajprenal.00215.2007

29 Roman RJ, Mattson DL and Cowley AW, Jr.: Measurement of regional blood flow in the kidney using laser-Doppler flowmetry. Methods Mol Med 51: 407-426, 2001. PMID: 21331733. DOI: 10.1385/1-59259-087-X:407

30 Pechman KR, De Miguel C, Lund H, Leonard EC, Basile DP and Mattson DL: Recovery from renal ischemia-reperfusion injury is associated with altered renal hemodynamics, blunted pressure natriuresis, and sodium-sensitive hypertension. Am J Physiol Regul Integr Comp Physiol 297: R1358-1363, 2009. PMID: 19710386. DOI: 10.1152/ajpregu.91022.2008

31 Zager RA, Johnson AC, and Becker K: Renal cortical lactate dehydrogenase: A useful, accurate, quantitative marker of in vivo tubular injury and acute renal failure. PLoS One 8: e66776, 2013. PMID: 23825563. DOI: 10.1371/journal.pone. 0066776

32 Galkina E and Ley K: Leukocyte recruitment and vascular injury in diabetic nephropathy. J Am Soc Nephrol 17: 368-377, 2006. PMID: 16394109. DOI: 10.1681/ASN.2005080859

33 Gollapudi P, Yoon JW, Gollapudi S, Pahl MV and Vaziri ND: Leukocyte toll-like receptor expression in end-stage kidney disease. Am J Nephrol 31: 247-254. PMID: 20090311. DOI: $10.1159 / 000276764$

34 Singleton JR, Smith AG, Russell JW and Feldman EL: Microvascular complications of impaired glucose tolerance. Diabetes 52: 2867-2873, 2003. PMID: 14633845. DOI: 10.2337/ diabetes.52.12.2867

35 Pacher P, Beckman JS and Liaudet L: Nitric oxide and peroxynitrite in health and disease. Physiol Rev 87: 315-424, 2007. PMID: 17237348. DOI: 10.1152/physrev.00029.2006

36 Evans JL, Goldfine ID, Maddux BA and Grodsky GM: Oxidative stress and stress-activated signaling pathways: a unifying hypothesis of type 2 diabetes. Endocr Rev 23: 599-622, 2002. PMID: 12372842. DOI: 10.1210/er.2001-0039

37 Yan Z, Yong-Guang T, Fei-Jun L, Fa-Qing T, Min T and Ya C: Interference effect of epigallocatechin-3-gallate on targets of nuclear factor kappaB signal transduction pathways activated by $\mathrm{EB}$ virus encoded latent membrane protein 1. Int J Biochem Cell Biol 36: 1473-1481, 2004. PMID: 15147726. DOI: 10.1016/ j.biocel.2003.10.024

38 Li JH, Huang XR, Zhu HJ, Johnson R and Lan HY: Role of TGF-beta signaling in extracellular matrix production under high glucose conditions. Kidney Int 63: 2010-2019, 2003. PMID: 12753288. DOI: 10.1046/j.1523-1755.2003.00016.x

39 Tergaonkar V: NFkappaB pathway: a good signaling paradigm and therapeutic target. Int J Biochem Cell Biol 38: 1647-1653, 2006. PMID: 16766221. DOI: 10.1016/j.biocel.2006.03.023

40 Zhang Y, Alexander PB and Wang XF: TGF-beta Family Signaling in the Control of Cell Proliferation and Survival. Cold Spring Harb Perspect Biol 9: a022145, 2017. PMID: 27920038. DOI: $10.1101 /$ cshperspect.a022145

41 Ogura Y, Ouchi N, Ohashi K, Shibata R, Kataoka Y, Kambara T, Kito T, Maruyama S, Yuasa D, Matsuo K, Enomoto T, Uemura Y, Miyabe M, Ishii M, Yamamoto T, Shimizu Y, Walsh $\mathrm{K}$ and Murohara T: Therapeutic impact of follistatin-like 1 on myocardial ischemic injury in preclinical models. Circulation 126: 1728-1738. PMID: 22929303. DOI: 10.1161/CIRCULATIONAHA.112.115089

42 Masaki M, Izumi M, Oshima Y, Nakaoka Y, Kuroda T, Kimura R, Sugiyama S, Terai K, Kitakaze M, Yamauchi-Takihara K, Kawase I, and Hirota H: Smad1 protects cardiomyocytes from ischemiareperfusion injury. Circulation 111: 2752-2759, 2005. PMID: 15911698. DOI: 10.1161/CIRCULATIONAHA.104.490946

43 Hohenstein B, Daniel C, Hausknecht B, Boehmer K, Riess R, Amann KU and Hugo CP: Correlation of enhanced thrombospondin-1 expression, TGF-beta signalling and proteinuria in human type-2 diabetic nephropathy. Nephrol Dial Transplant 23: 3880-3887, 2008. PMID: 18676351. DOI: 10.1093/ndt/gfn399

44 Wang Y and Wang DH: Protective effect of TRPV1 against renal fibrosis via inhibition of TGF-beta/Smad signaling in DOCAsalt hypertension. Mol Med 17: 1204-1212. PMID: 21792478. DOI: $10.2119 / \mathrm{molmed} .2011 .00063$

45 Vallon V: The proximal tubule in the pathophysiology of the diabetic kidney. Am J Physiol Regul Integr Comp Physiol 300: R1009-1022. PMID: 21228342. DOI: 10.1152/ajpregu.00809. 2010

46 Prasad P, Li LP, Halter S, Cabray J, Ye M and Batlle D: Evaluation of renal hypoxia in diabetic mice by BOLD MRI. Invest Radiol 45: 819-822, 2010. PMID: 20829708. DOI: 10.1097/RLI.0b013e3181ec9b02

47 Ye J, Gao Z, Yin J and He Q: Hypoxia is a potential risk factor for chronic inflammation and adiponectin reduction in adipose tissue of ob/ob and dietary obese mice. Am J Physiol Endocrinol Metab 293: E1118-1128, 2007. PMID: 17666485. DOI: 10.1152/ajpendo.00435.2007

48 Zhang H, Akman HO, Smith EL, Zhao J, Murphy-Ullrich JE and Batuman OA: Cellular response to hypoxia involves signaling via Smad proteins. Blood 101: 2253-2260, 2003. PMID: 12411310. DOI: $10.1182 /$ blood-2002-02-0629

49 Houstis N, Rosen ED and Lander ES: Reactive oxygen species have a causal role in multiple forms of insulin resistance. Nature 440: 944-948, 2006. PMID: 16612386. DOI: 10.1038/ nature 04634

50 Franco-Penteado CF, De Souza IA, Camargo EA, Teixeira SA, Muscara MN, De Nucci G, and Antunes E: Mechanisms involved in the enhancement of allergic airways neutrophil influx by permanent $\mathrm{C}$-fiber degeneration in rats. J Pharmacol Exp Ther 313: 440-448, 2005. PMID: 15579495. DOI: 10.1124/ jpet.104.078147

51 Reichlin S: Neuroendocrine-immune interactions. N Engl J Med 329: 1246-1253, 1993. PMID: 8105378. DOI: 10.1056/ NEJM199310213291708 
52 Li W, Wang T, Ma C, Xiong T, Zhu Y and Wang X: Calcitonin gene-related peptide inhibits interleukin-1beta-induced endogenous monocyte chemoattractant protein-1 secretion in type II alveolar epithelial cells. Am J Physiol Cell Physiol 291: C456-465, 2006. PMID: 16597919. DOI: 10.1152/ajpcell. 00538.2005

53 Nong YH, Titus RG, Ribeiro JM and Remold HG: Peptides encoded by the calcitonin gene inhibit macrophage function. J Immunol 143: 45-49, 1989. PMID: 2543703.

54 Monneret G, Pachot A, Laroche B, Picollet J and Bienvenu J: Procalcitonin and calcitonin gene-related peptide decrease LPSinduced tnf production by human circulating blood cells. Cytokine 12: 762-764, 2000. PMID: 10843760. DOI: 10.1006/ cyto.1999.0607

55 Asahina A, Moro O, Hosoi J, Lerner EA, Xu S, Takashima A and Granstein RD: Specific induction of cAMP in Langerhans cells by calcitonin gene-related peptide: relevance to functional effects. Proc Natl Acad Sci USA 92: 8323-8327, 1995. PMID: 7667288. DOI: $10.1073 /$ pnas.92.18.8323
56 Ichinose M and Sawada M: Enhancement of phagocytosis by calcitonin gene-related peptide (CGRP) in cultured mouse peritoneal macrophages. Peptides 17: 1405-1414, 1996. PMID: 8971938. DOI: 10.1016/s0196-9781(96)00198-2

57 Bowers MC, Katki KA, Rao A, Koehler M, Patel P, Spiekerman A, DiPette DJ and Supowit SC: Role of calcitonin gene-related peptide in hypertension-induced renal damage. Hypertension 46: 51-57, 2005. PMID: 15928032. DOI: 10.1161/01.HYP 0000168926.44648.ed

Received March 30, 2020

Revised May 19, 2020

Accepted May 20, 2020 